\title{
Optimizing of the Higher Order Mode Dampers in the 56MHz SRF Cavity
}

Q. Wu, I. Ben-Zvi

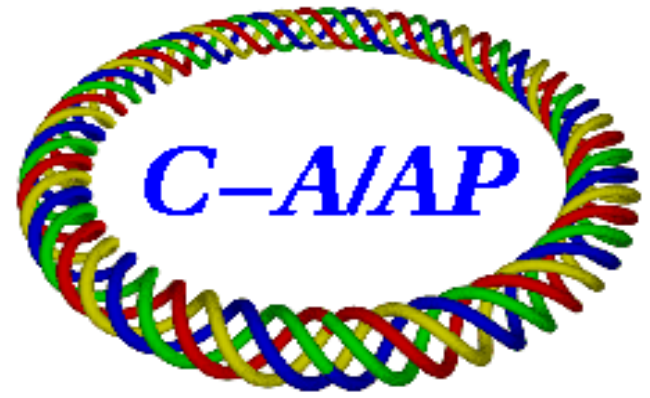

\section{Collider-Accelerator Department Brookhaven National Laboratory \\ Upton, NY 11973}

Notice: This document has been authorized by employees of Brookhaven Science Associates, LLC under Contract No. DE-AC02-98CH10886 with the U.S. Department of Energy. The United States Government retains a nonexclusive, paid-up, irrevocable, world-wide license to publish or reproduce the published form of this document, or allow others to do so, for United States Government purposes. 


\title{
Optimizing of the Higher Order Mode Dampers in the 56MHz SRF Cavity
}

\author{
Q. Wu, I. Ben-Zvi
}

Dec. 9, 2009

\begin{abstract}
Earlier, we reported that a $56 \mathrm{MHz}$ cavity was designed for a luminosity upgrade of the RHIC, and presented the requirements for Higher Order Mode (HOM) damping, the design of the HOM dampers, along with measurements and simulations of the HOM dampers.

In this report, we describe our optimization of the dampers' performance, and the modifications we made to their original design. We also optimized the number of the HOM dampers, and tested different configurations of locations for them.
\end{abstract}

\section{Optimization of the HOM damper and chemical port}

The optimization of our original design of the HOM dampers for the $56 \mathrm{MHz}$ cavity [1] was based on the following criteria:

a. All monopole and dipole HOMs below $1 \mathrm{GHz}$ should be damped effectively. All other HOMs with a high R/Q should be similarly treated.

b. The change in the fundamental mode frequency due to inserting the damper should be well quantified.

c. The HOM dampers should be inserted through the chemical cleaning ports located at the rear of the cavity.

d. The field enhancement around the HOM dampers and ports should be such that the peak surface-magnetic fields do not exceed the maximum in the rest of the cavity.

e. In considering the smallest gap between the port and the damper, the HOM damper must never be at a high voltage such that might lead to an electrical breakdown.

f. The ease of fabrication by manufacturers should be assured.

\subsection{Original Model}

The original design of the HOM damper, shown in Figure 1, was the outcome of a former study [2]. The findings obtained from Microwave Studio simulations with this original design had the following parameters [Table 1]: 
Table 1: Parameters of original design of HOM damper

\begin{tabular}{|c|c|}
\hline Dimension of damper inner loop & $6 \mathrm{~cm} \mathrm{x} 2.88 \mathrm{~cm}$ \\
\hline Damper width & $2 \mathrm{~cm}$ \\
\hline Damper thickness & $0.3 \mathrm{~cm}$ \\
\hline Inner conductor radius & $0.76 \mathrm{~cm}$ \\
\hline Damper shape & All sharp edges \\
\hline Port shape & Round, $\mathrm{r}=1.74 \mathrm{~cm}$ \\
\hline Mesh size around damper & $\sim 0.3 \mathrm{~cm}$ \\
\hline Minimum mesh size & $0.24 \mathrm{~cm}$ \\
\hline Maximum mesh size & $1.5 \mathrm{~cm}$ \\
\hline Mesh cell number & 833382 \\
\hline Equilibrate mesh ratio & 1.4 \\
\hline Accuracy & $1 \mathrm{E}-6$ \\
\hline
\end{tabular}

Figure 1 shows the original design of the HOM damper and the inserted configuration. The damper is designed such that it can be inserted into the cavity from the chemical-cleaning port, located at the cavity's rear end [2]. The size of the damper's loop was optimized to assure maximum coupling of the magnetic field, while also leaving it accessible through the 1.5" diameter opening of the chemical port.

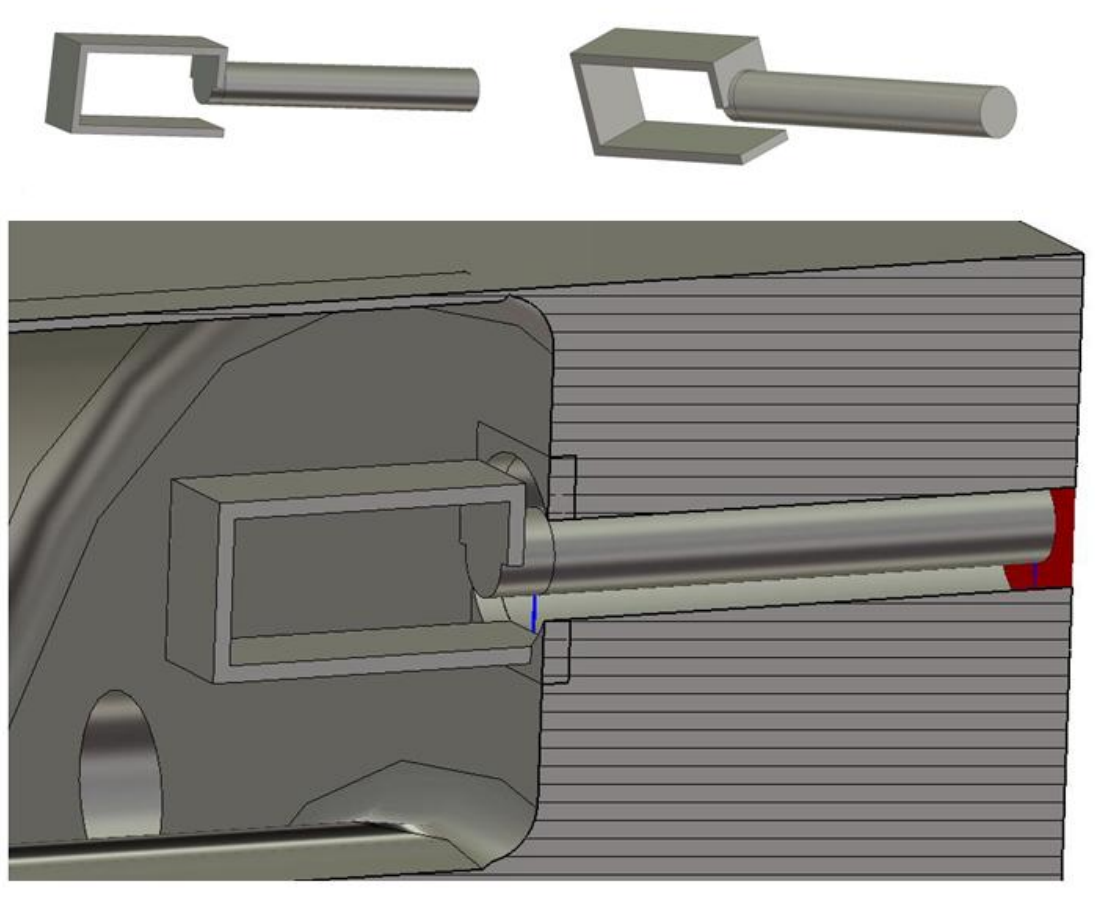

Figure 1: The original design of HOM damper. 
Table 2 lists the results of the Microwave Studio (MWS) [3] simulation of the $56 \mathrm{MHz}$ cavity's fundamental mode with single HOM damper.

Table 2: MWS simulation results of the fundamental mode of the $56 \mathrm{MHz}$ cavity with one damper in its original design.

\begin{tabular}{|c|c|}
\hline Fundamental mode frequency & $56.2383 \mathrm{MHz}$ \\
\hline External Q factor & 4255 \\
\hline $\mathrm{R} / \mathrm{Q}$ & 79.9 \\
\hline $\mathrm{V}_{\mathrm{acc}}$ & $0.168 \mathrm{MV}$ \\
\hline $\mathrm{Q}_{0}$ & 10198 \\
\hline Shunt impedance & $8.15 \mathrm{E} 5 \mathrm{Ohm}$ \\
\hline $\mathrm{V}_{\text {damper }}$ & $1630 \mathrm{~V}$ \\
\hline
\end{tabular}

As Figure 1 shows, all the edges and corners of the damper and the chemical ports are sharp. This easily engenders a considerable enhancement of in the local electric field, thereby increasing the possibility of causing electrical break down and quenching in the cavity. The field around the port can be obtained from the MWS simulation. 

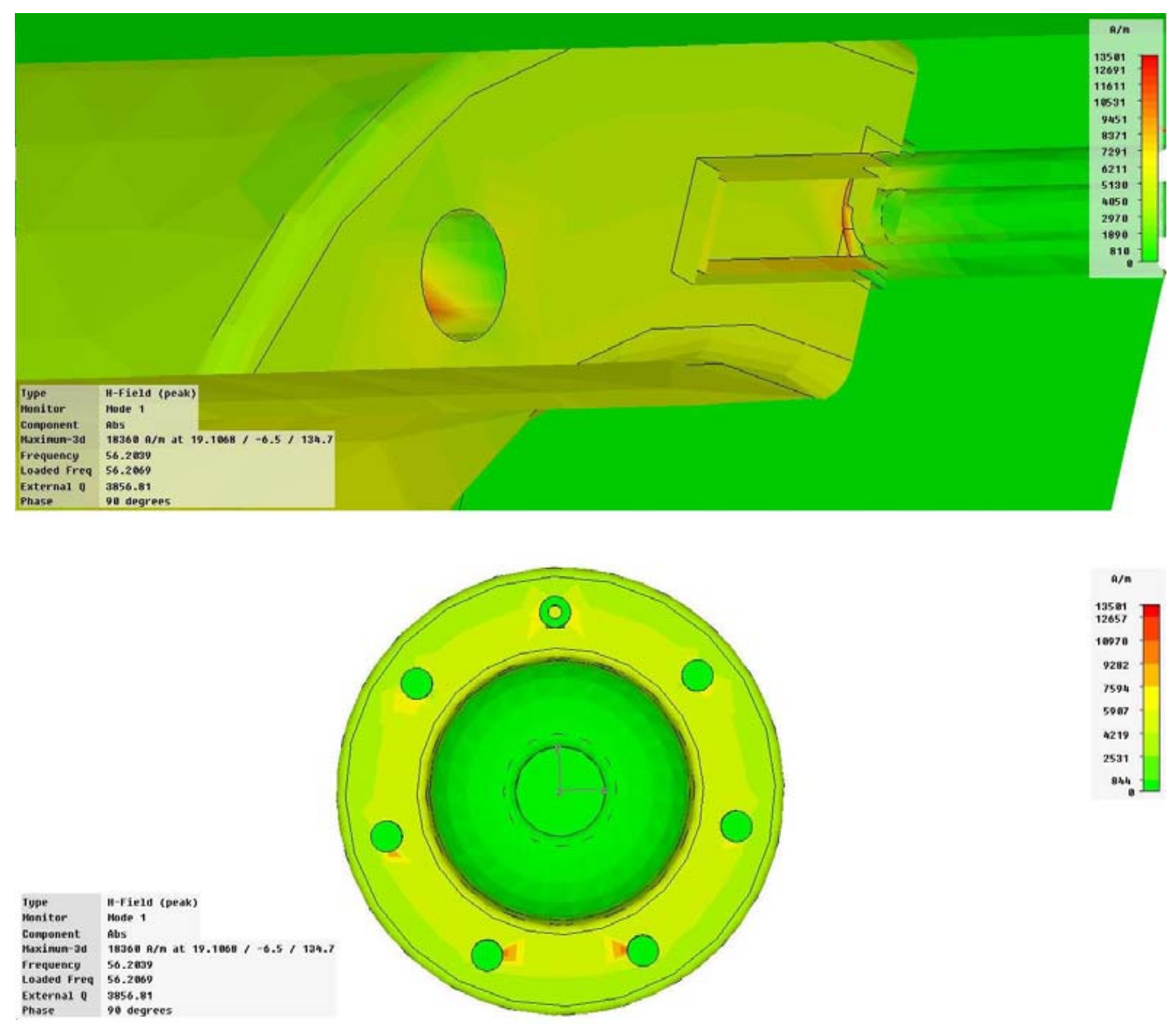

Figure 2: Peak magnetic field at HOM damper port. Top: Cross section view. Bottom: Rear end view.

The $56 \mathrm{MHz}$ cavity will be operated at the store stage for the RHIC; thus, the HOM damper then will experience the cavity's full voltage, which is designed to reach $2.5 \mathrm{MV}$. The highest corresponding magnetic field is generated at the sharp edge of the chemical port, as depicted in Figure 2; it is of the magnitude of $2.6 \times 10^{8} \mathrm{~A} / \mathrm{m}$ (the normalization factor of this cavity is 14.66 for the MWS simulation). This strong field will generate heat locally, and cause a rapid rise in the cavity's temperature. Blending of the ports' edge is essential for lowering the peak surface-magnetic-field.

\subsection{Modified design of the damper and chemical ports}

To avoid a high peak field that might cause electrical break down, we need to smooth all the sharp edges on the dampers while maintaining the same inner loop area. 
Figure 3 shows the modified HOM damper we designed. . The cross-section of the loop is elliptical and the corners are rounded, while the inner area of the loop remains unchanged, i.e. $6 \mathrm{~cm}$ by $2.88 \mathrm{~cm}$. The width and the thickness of the loop also are unchanged as are the values of the long and short axes of the new elliptical cross-section.

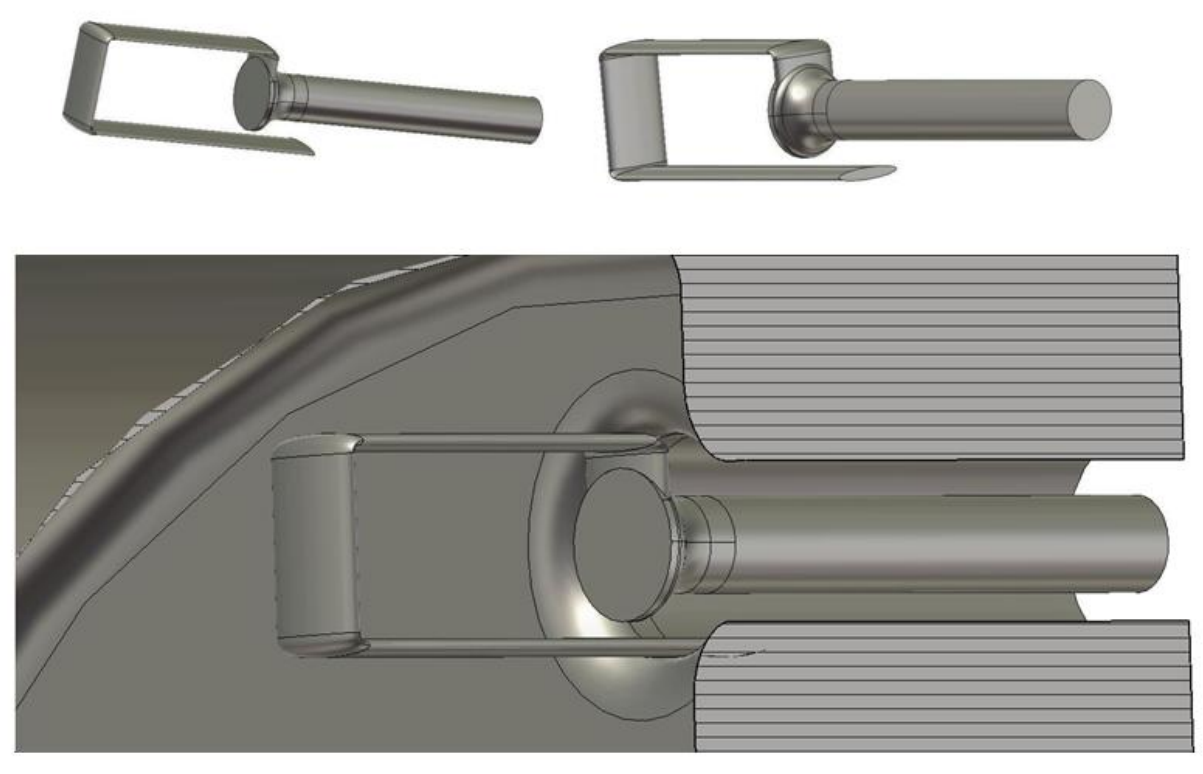

Figure 3: Modified HOM damper.

The radius of the connection of inner conductor and the loop of the HOM damper changes gradually, so that the radial ratio of the coaxial structure always remains constant, thereby ensuring that all HOM modes can be coupled out to the external load.

Figure 4 illustrates the magnetic field at the end of the cavity with HOM damper inserted; the maximum field on the damper is $8.4 \times 10^{4} \mathrm{~A} / \mathrm{m}$. This value is only $1 / 3$ of the that in our original design, and even lower than the field generated on the cavity's shell, which is $9.5 \times 10^{4} \mathrm{~A} / \mathrm{m}$. The peak field at the port opening is $1.2 \times 10^{8} \mathrm{~A} / \mathrm{m}$.

The modified HOM damper maintains the original inner loop area and thickness, thus preserving the parameters of the performance table. We checked this by an MWS simulation that we discuss in the next section. 


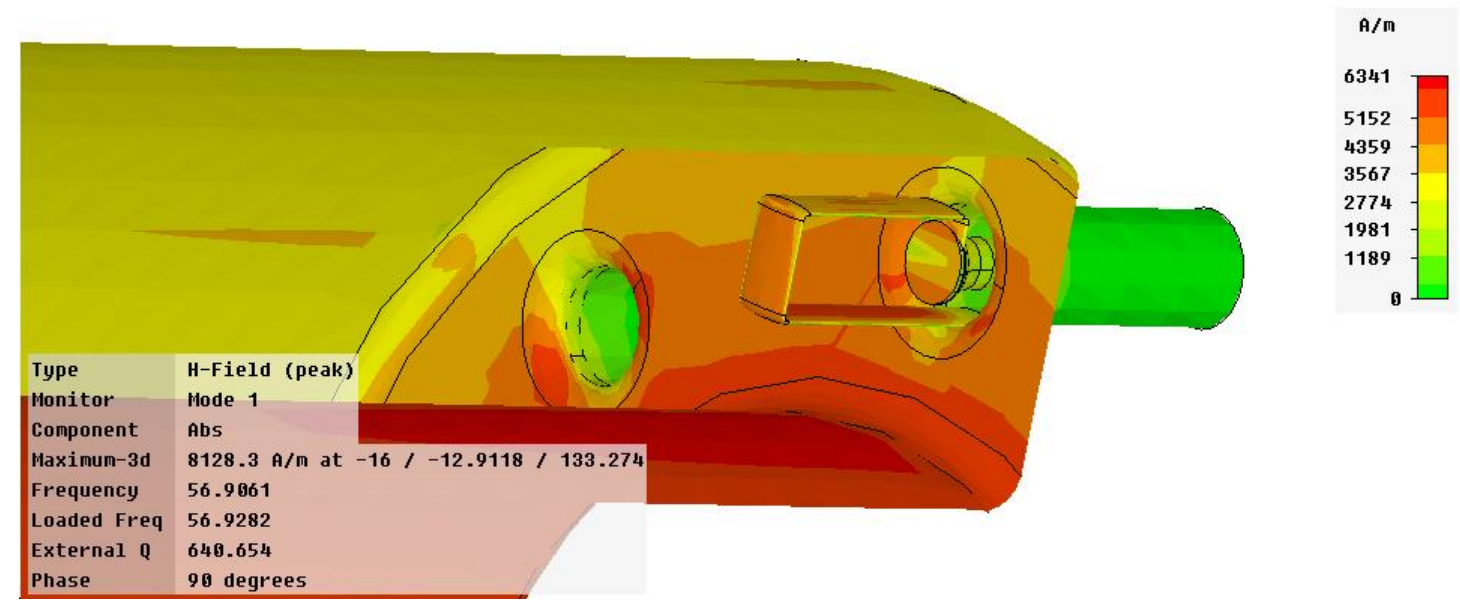

Figure 4: Maximum magnetic field around the HOM damper for the fundamental mode of operation.

We modified the chemical port is further to lower the electric field at its opening. Our final design is depicted in Figure 5. The field was calculated with the software ANSYS [4] it revealed that the peak field at the chemical cleaning port decreased to the same level as that at the end of the inner cavity.
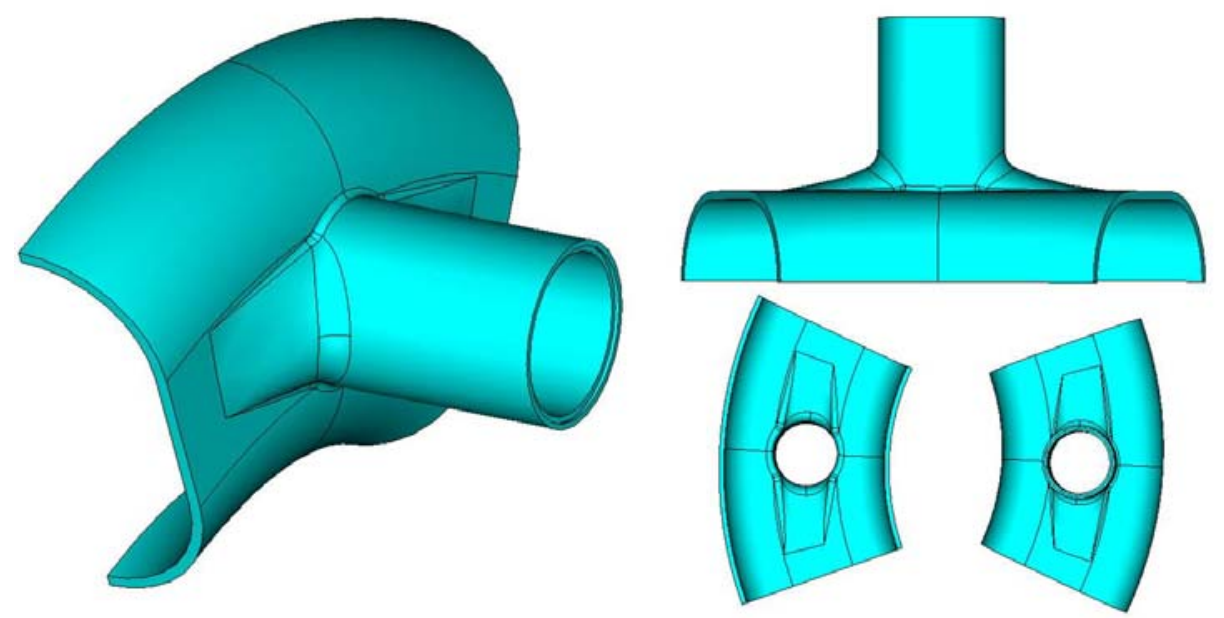

Figure 5: Final design of chemical port. [5] (M. Grau, private discussion) 


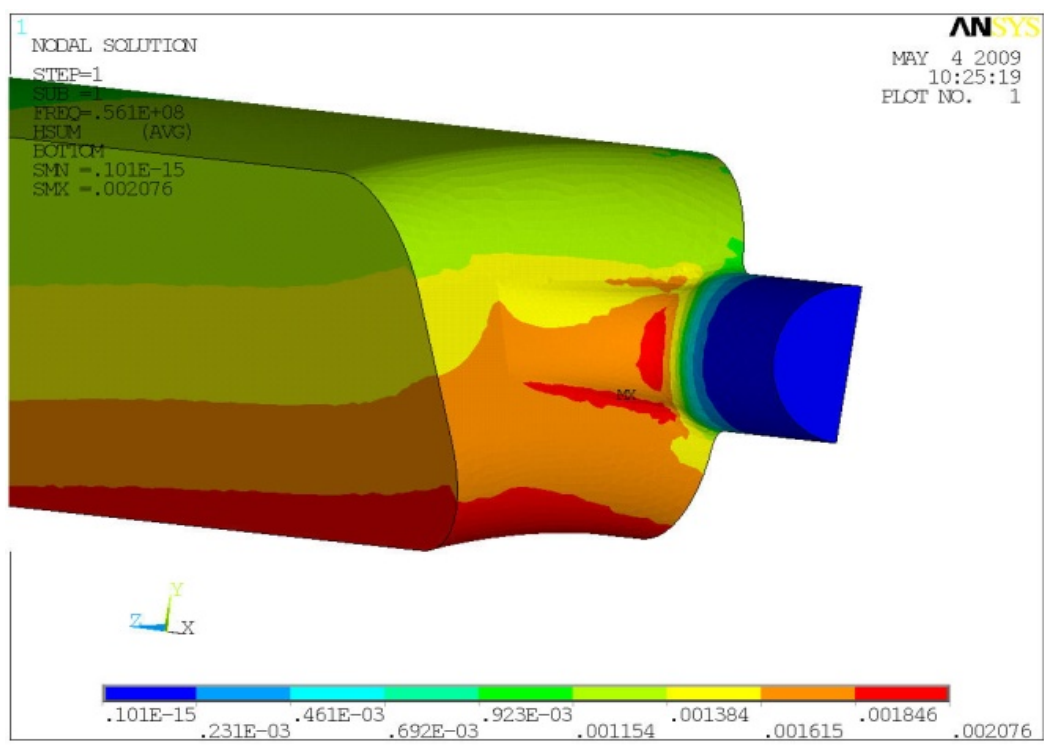

Figure 6: Magnetic field at the chemical port and rear end of cavity in final design. [6] (C. Pai, private discussion)

This latest design of the chemical port and the HOM damper greatly will reduces the risk of magnetic break down, and quenching of the cavity. 


\section{The performance of the modified HOM damper}

With the modified HOM damper, we carried out simulations with Microwave Studio (MWS) to demonstrate its damping effect in the $56 \mathrm{MHz}$ cavity.

\subsection{Damping with 1 HOM damper}

The HOM damper inner area was optimized with only 1 damper present [2]. Table 3 shows the damping effect of this one damper located in the chemical port.

Table 3: MWS simulation of frequencies and $\mathrm{Q}_{\mathrm{L}} \mathrm{s}$ in the $56 \mathrm{MHz}$ cavity with 1 modified damper.

\begin{tabular}{cc|cc}
\hline Frequency $[\mathrm{MHz}]$ & $\mathrm{Q}_{\mathrm{L}}$ & Frequency $[\mathrm{MHz}]$ & $\mathrm{Q}_{\mathrm{L}}$ \\
\hline 56.182 & 3828 & 785.44 & 5532 \\
167.53 & 1814 & 786.73 & 7619 \\
254.38 & 248 & 839.02 & 5519 \\
260.38 & 6412 & 840.13 & 4879 \\
276.51 & 1806 & 884.84 & 18918 \\
314.46 & 2168 & 895.97 & 24324 \\
377.84 & 2236 & 903.98 & 64555 \\
393.05 & 1528 & 903.22 & 104470 \\
474.56 & 2789 & 949.52 & 153460 \\
573.20 & 3494 & 968.72 & 23131 \\
525.27 & 6771 & 971.41 & 49716 \\
578.64 & 976.50 & 6527 \\
579.73 & 11802 & 986.44 & 5407 \\
647.59 & 1207 & 1002.71 & 4349 \\
670.75 & 3135 & 1003.21 & 6389 \\
677.59 & 2284 & 1106.15 & 3282 \\
722.69 & 2989 & 1122.23 & 1410 \\
727.36 & 75269 & 1131.10 & 8651 \\
747.10 & 2968 & 1158 & 2063 \\
752.41 & 22054 & & \\
\hline
\end{tabular}

Table 3 shows that with one damper some frequencies of the HOMs in the $900 \mathrm{MHz}$ range are not depressed effectively. Ideally, in the presence of an HOM damper, all the modes would be extracted from the cavity, and the fundamental mode then would be reflected back by the high pass filter behind the damper. However, the size of the HOM damper is limited in this design of the cavity by the accessible radius and location of the chemical port. With only $1 \mathrm{HOM}$ 
damper, it would be difficult to effectively suppress modes with numbers of poles higher than 2 , e.g. quadrupole, sextupole.

In addition, the tolerances of HOMs also are highly dependent on the R/Qs, or the shunt impedance obtained from the product of $\mathrm{Q}_{\mathrm{L}}$ and $\mathrm{R} / \mathrm{Q}$ for each mode.

Therefore, we need to increase the number of the HOM dampers and change the configuration of their locations to enhance the damping effect. The R/Q and shunt impedance of each mode should be calculated to quantify the tolerance of each mode and improve the efficiency of damping.

\subsection{Damping with 4 HOM dampers at symmetrical locations}

There are 8 existing chemical ports at the rear end of the cavity two of which are occupied by the fundamental coupler and the pickup. The 6 remaining chemical ports can be used for HOM dampers and their locations chosen. We explored the effects using $4 \mathrm{HOM}$ dampers at symmetrical ports, as shown in Figure 7.

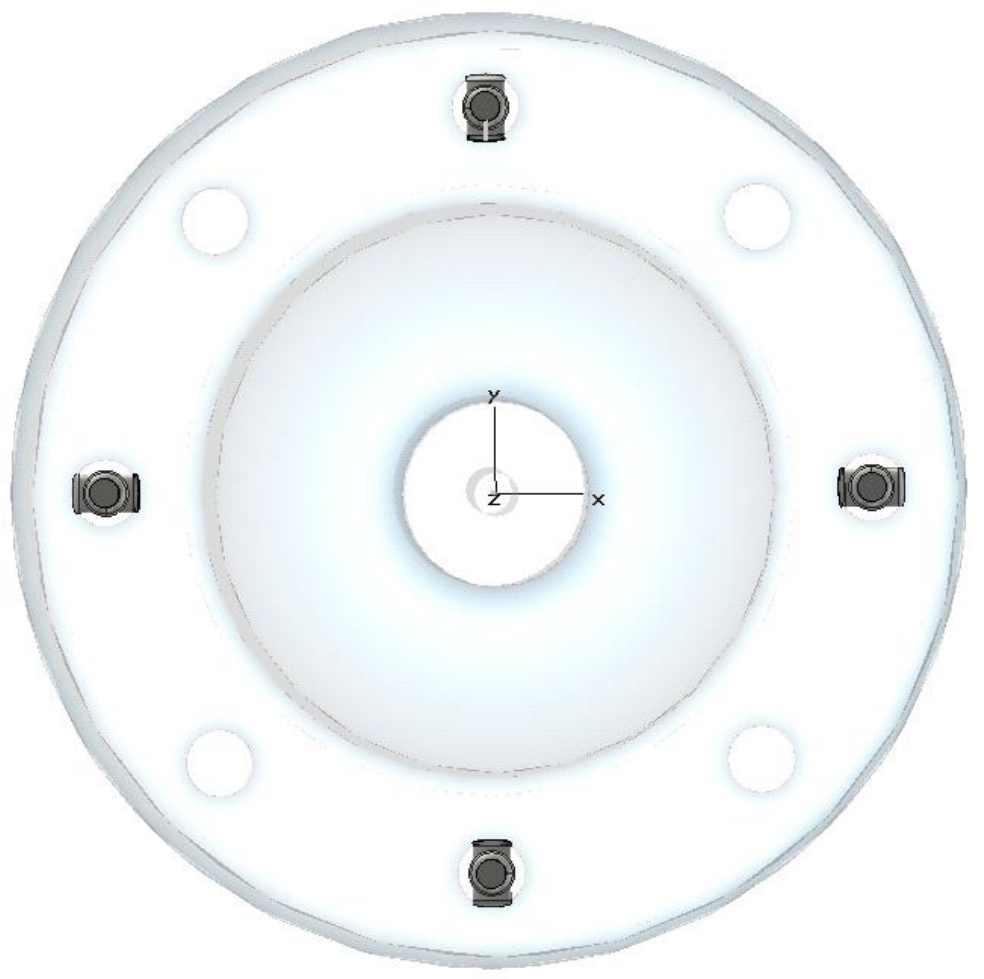

Figure 7: Rear view of the cavity with $4 \mathrm{HOM}$ dampers inserted in symmetrical ports. 
The damping effect in such a configuration is given in Table 4 from MWS simulations of frequency and $\mathrm{Q}_{\mathrm{L}}$.

Table 4: MWS simulations of frequencies and $\mathrm{Q}_{\mathrm{L}} \mathrm{S}$ in the $56 \mathrm{MHz}$ cavity with 4 modified dampers inserted in symmetrical chemical ports.

\begin{tabular}{|c|c|c|c|}
\hline Frequency [MHz] & $\mathrm{Q}_{\mathrm{L}}$ & Frequency $[\mathrm{MHz}]$ & $\mathrm{Q}_{\mathrm{L}}$ \\
\hline 56.197 & 933 & 722.51 & $3.44 \mathrm{E}+04$ \\
\hline 167.68 & 451 & 726.68 & $9.18 \mathrm{E}+08$ \\
\hline 259.82 & 3208 & 727.25 & 727 \\
\hline 259.78 & 3218 & 746.83 & $1.36 \mathrm{E}+04$ \\
\hline 275.9 & 454 & 747.02 & $1.40 \mathrm{E}+04$ \\
\hline 314.32 & 1105 & 751.25 & 1350 \\
\hline 314.29 & 1107 & 751.11 & 1350 \\
\hline 377.96 & 547 & 784.92 & 1140 \\
\hline 392.947 & 782 & 786.57 & 5340 \\
\hline 392.942 & 784 & 786.77 & 5580 \\
\hline 474.57 & 636 & 813.12 & $1.16 \mathrm{E}+09$ \\
\hline 484.111 & 748 & 813.87 & 988 \\
\hline 484.108 & 748 & 836.36 & 2610 \\
\hline 490.24 & $4.28 \mathrm{E}+08$ & 836.28 & 2660 \\
\hline 491.35 & 6080 & 839.49 & 0.634 \\
\hline 523.98 & $9.73 \mathrm{E}+09$ & 839.67 & 3750 \\
\hline 525.28 & 1760 & 892.92 & $1.35 \mathrm{E}+04$ \\
\hline 572.87 & 707 & 902.17 & $3.58 \mathrm{E}+09$ \\
\hline 577.36 & $1.11 \mathrm{E}+08$ & 902.42 & $4.47 \mathrm{E}+04$ \\
\hline 578.91 & 992 & 903.58 & $1.50 \mathrm{E}+05$ \\
\hline 579.24 & 829 & 903.71 & $9.60 \mathrm{E}+07$ \\
\hline 579.23 & 831 & 932.47 & 9240 \\
\hline 646.1 & $1.50 \mathrm{E}+09$ & 932.55 & $1.33 \mathrm{E}+04$ \\
\hline 647.88 & 765 & 949.21 & $6.12 \mathrm{E}+04$ \\
\hline 670.12 & 1060 & 952.89 & $8.96 \mathrm{E}+10$ \\
\hline 670.1 & 1060 & 968.44 & $1.03 \mathrm{E}+04$ \\
\hline 677.49 & 807 & 972.11 & $3.57 \mathrm{E}+10$ \\
\hline 722.28 & $3.32 \mathrm{E}+04$ & 975.85 & 279 \\
\hline
\end{tabular}

The configuration and R/Q of each mode also was simulated with MWS. 
Table 5: MWS simulation of frequencies, mode configurations, and R/Qs in the $56 \mathrm{MHz}$ cavity with 4 modified dampers inserted in symmetrical chemical ports. (Mode configuration: M, monopole; D, dipole; S, sextupole; and, Q, quadrupole)

\begin{tabular}{cccc|cccc}
\hline $\begin{array}{c}\text { Frequency } \\
{[\mathrm{MHz}]}\end{array}$ & $\begin{array}{c}\text { Mode } \\
\text { Config. }\end{array}$ & $\mathrm{R} / \mathrm{Q}[\Omega]$ & $\mathrm{R}_{\mathrm{SH}}[\Omega / \mathrm{cm}]$ & $\begin{array}{c}\text { Frequency } \\
{[\mathrm{MHz}]}\end{array}$ & $\begin{array}{c}\text { Mode } \\
\text { Config. }\end{array}$ & $\mathrm{R} / \mathrm{Q}[\Omega]$ & $\mathrm{R}_{\mathrm{SH}}[\Omega / \mathrm{cm}]$ \\
\hline 56.197 & $\mathrm{M}$ & 77.8 & 538 & 722.51 & $\mathrm{~S}$ & $1.31 \mathrm{E}-05$ & 0.068 \\
167.68 & $\mathrm{M}$ & 31.3 & 105 & 726.68 & $\mathrm{Q}$ & $2.30 \mathrm{E}-04$ & 32134 \\
259.82 & $\mathrm{D}$ & 8.1 & 1415 & 727.25 & $\mathrm{Q}$ & $2.50 \mathrm{E}-04$ & 0.028 \\
259.78 & $\mathrm{D}$ & 9.8 & 1715 & 746.83 & $\mathrm{~S}$ & $1.50 \mathrm{E}-13$ & $3.19 \mathrm{E}-10$ \\
275.9 & $\mathrm{M}$ & 24.66 & 83 & 747.02 & $\mathrm{~S}$ & $1.50 \mathrm{E}-03$ & 3.28 \\
314.32 & $\mathrm{D}$ & 14.3 & 1041 & 751.25 & $\mathrm{D}$ & 22.5 & 4770 \\
314.29 & $\mathrm{D}$ & 14.3 & 1043 & 751.11 & $\mathrm{D}$ & 22.7 & 4814 \\
377.96 & $\mathrm{M}$ & 26.9 & 109 & 784.92 & $\mathrm{M}$ & 3.8 & 32 \\
392.947 & $\mathrm{D}$ & 13.4 & 864 & 786.57 & $\mathrm{~S}$ & $1.11 \mathrm{E}-05$ & 0.0098 \\
392.942 & $\mathrm{D}$ & 13.6 & 876 & 786.77 & $\mathrm{~S}$ & $3.90 \mathrm{E}-05$ & 0.036 \\
474.57 & $\mathrm{M}$ & 22.15 & 105 & 813.12 & $\mathrm{Q}$ & $4.00 \mathrm{E}-04$ & 79019 \\
484.111 & $\mathrm{D}$ & 13.3 & 1011 & 813.87 & $\mathrm{Q}$ & $4.00 \mathrm{E}-04$ & 0.067 \\
484.108 & $\mathrm{D}$ & 13.3 & 1011 & 836.36 & $\mathrm{D}$ & 9.0 & 4112 \\
490.24 & $\mathrm{Q}$ & $1.96 \mathrm{E}-05$ & 861 & 836.28 & $\mathrm{D}$ & 9.1 & 4237 \\
491.35 & $\mathrm{Q}$ & $3.77 \mathrm{E}-05$ & 0.024 & 839.49 & $\mathrm{~S}$ & $7.90 \mathrm{E}-04$ & $8.81 \mathrm{E}-5$ \\
523.98 & $\mathrm{Q}$ & $5.35 \mathrm{E}-05$ & 57126 & 839.67 & $\mathrm{~S}$ & $7.00 \mathrm{E}-04$ & 0.46 \\
525.28 & $\mathrm{Q}$ & $8.83 \mathrm{E}-05$ & 0.017 & 892.92 & $\mathrm{M}$ & 2.62 & 262 \\
572.87 & $\mathrm{M}$ & 12.89 & 68 & 902.17 & $\mathrm{Q}$ & $8.80 \mathrm{E}-04$ & 595268 \\
577.36 & $\mathrm{Q}$ & $1.33 \mathrm{E}-04$ & 1785 & 902.42 & $\mathrm{Q}$ & $3.50 \mathrm{E}-04$ & 2.96 \\
578.91 & $\mathrm{Q}$ & $1.59 \mathrm{E}-04$ & 0.019 & 903.58 & $\mathrm{~S}$ & $2.43 \mathrm{E}-06$ & 0.069 \\
579.24 & $\mathrm{D}$ & 15.4 & 1551 & 903.71 & $\mathrm{~S}$ & $3.00 \mathrm{E}-05$ & 545 \\
579.23 & $\mathrm{D}$ & 15.4 & 1548 & 932.47 & $\mathrm{D}$ & 2.7 & 4873 \\
646.1 & $\mathrm{Q}$ & $1.39 \mathrm{E}-04$ & 28214 & 932.55 & $\mathrm{D}$ & 2.8 & 7150 \\
647.88 & $\mathrm{Q}$ & $1.89 \mathrm{E}-04$ & 0.020 & 949.21 & $\mathrm{O}$ & $1.40 \mathrm{E}-05$ & 0.17 \\
670.12 & $\mathrm{D}$ & 22.4 & 3338 & 952.89 & $\mathrm{O}$ & $3.34 \mathrm{E}-10$ & 5.97 \\
670.1 & $\mathrm{D}$ & 22.5 & 3346 & 968.44 & $\mathrm{O}$ & $2.60 \mathrm{E}-05$ & 0.054 \\
677.49 & $\mathrm{M}$ & 6.64 & 40 & 972.11 & $\mathrm{O}$ & $2.20 \mathrm{E}-09$ & 16.0 \\
722.28 & $\mathrm{~S}$ & $1.14 \mathrm{E}-05$ & 0.057 & 975.85 & $\mathrm{~S}$ & $1.00 \mathrm{E}-05$ & 0.00057 \\
\hline & & & & & & & \\
\hline
\end{tabular}

The R/Qs of the cavity and shunt impedances per unit length for the monopoles are defined as:

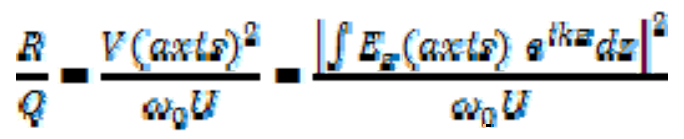




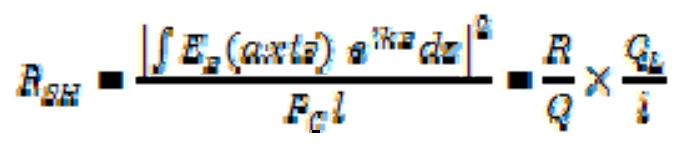

Both R/Qs and shunt impedances of the cavity for the dipoles are defined as:

$$
\begin{aligned}
& \frac{R}{Q}=\frac{1}{k^{2} 1 \mathrm{~cm}^{2}} \frac{V(1 \mathrm{~cm})^{2}}{\omega_{0} U}=\frac{1}{k^{2} 1 \mathrm{~cm}^{2}} \frac{\left.\left|\int E_{g}(1 \mathrm{~cm})\right|_{\max } e^{t k z} d z\right|^{2}}{\omega_{0} U} \\
& R_{S H}=k \frac{1}{k^{2} 1 \mathrm{~cm}^{2}} \frac{\left|\int E_{g}(1 \mathrm{~cm}) \theta^{i k z} d g\right|^{2}}{F_{Q}}=k \frac{R}{Q} \times Q_{L}
\end{aligned}
$$

Both $\mathrm{R} / \mathrm{Qs}$ and shunt impedances of the cavity for modes other than monopole and dipole are defined as:

$$
\begin{aligned}
& \frac{R}{Q}=\frac{V(1 \mathrm{~mm})^{2}}{\omega_{0} U}=\frac{\left.\left|\int E_{g}(1 \mathrm{~cm})\right|_{\max } e^{i k z} d z\right|^{2}}{\omega_{0} U} \\
& R_{S H}=k \frac{\left.\left|\int E_{z}(1 \mathrm{~cm})\right|_{\max } e^{t k a} d z\right|^{2}}{I_{C}}=k \frac{E}{Q} \times Q_{L}
\end{aligned}
$$

In all equations above, $z$ is the direction along the center axis, and $E_{a}\left(\alpha x s^{\prime}\right)$ is the electric field in $z$ direction on the axis; $E_{z}(1 \mathrm{~cm})$ is the axial electric-field with $1 \mathrm{~cm}$ offset to the center. $P_{\sigma}$ is the power loss of the specified mode due to the HOM damper. Thus, $V(1 \mathrm{~cm})$ is the accelerating voltage of each mode with an offset of $1 \mathrm{~cm} . l$ is the length of the cavity. Also, $\omega_{0}$ and $U$ are, respectively, the frequency and stored energy of the specified mode. In the MWS simulation, the cavity material is lossless, thus $Q_{\boldsymbol{m}}=Q_{\mathrm{L}}$.

In this configuration of the locations of the HOM dampers, most of the higher order modes are damped effectively. However, quadrupoles with a configuration of 45 rotated from the location of the HOM dampers barely are damped due to the orthogonality between them. All these quadrupoles have a shunt impedance of $1 \times 10^{4} \Omega / \mathrm{cm}$. Quadrupoles do not affect the performance of the cavity as much as do the monopoles and dipoles, but their effect still is nonnegligible with such a high R/Q and accumulation as the beam stores in RHIC. 


\subsection{Damping with 4 HOM dampers at asymmetrical locations}

To effect a compromise between all the HOMs and optimize the damping effeciency, the 4 HOM dampers must be placed asymmetrically.

We chose the 4 locations shown in Figure 8.

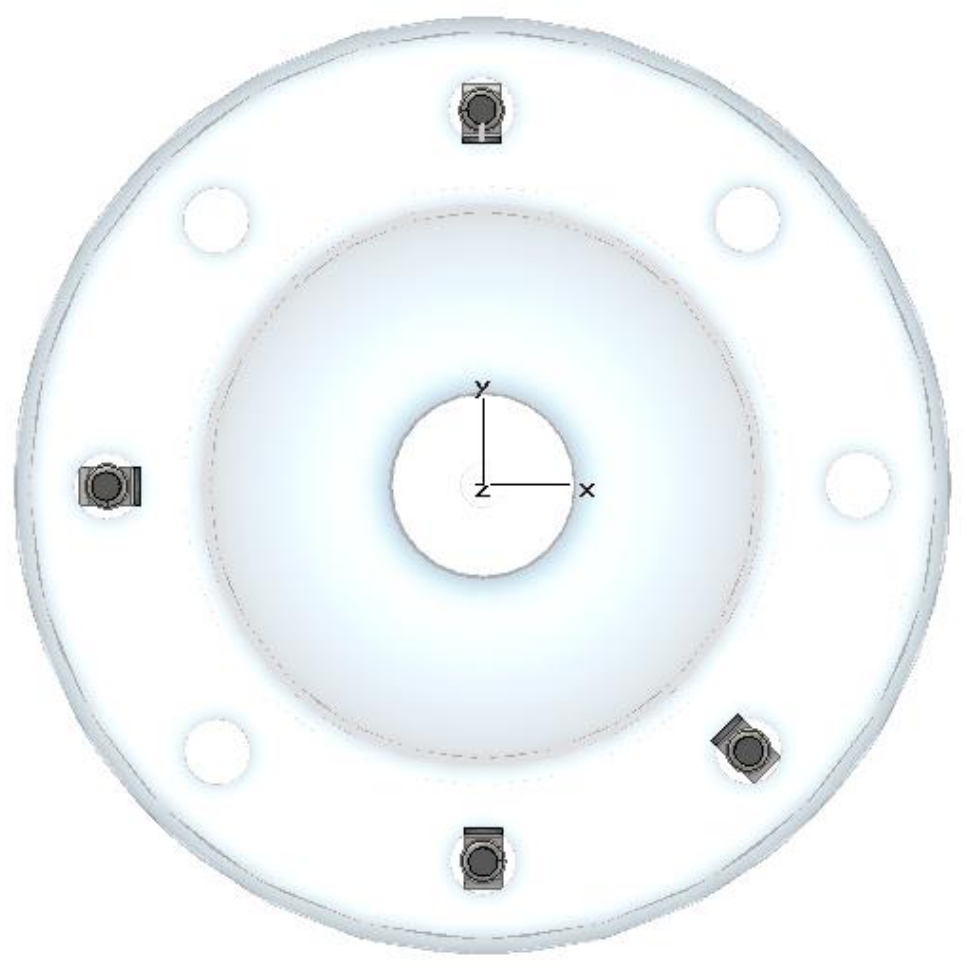

Figure 8: Rear view of the cavity with 4 HOM dampers inserted in asymmetrical ports. 
Table 6: MWS simulation of frequencies and $\mathrm{Q}_{\mathrm{L}} \mathrm{s}$ in the $56 \mathrm{MHz}$ cavity with 4 modified dampers inserted in asymmetrical chemical ports.

\begin{tabular}{|c|c|c|c|}
\hline Frequency $[\mathrm{MHz}]$ & $\mathrm{Q}_{\mathrm{L}}$ & Frequency $[\mathrm{MHz}]$ & $\mathrm{Q}_{\mathrm{L}}$ \\
\hline 56.231 & 940 & 722.661 & 28425 \\
\hline 167.456 & 438 & 726.747 & 953 \\
\hline 260.445 & 3817 & 726.786 & 4381 \\
\hline 261.133 & 2519 & 746.283 & 15679 \\
\hline 278.583 & 428 & 747.159 & 9811 \\
\hline 314.605 & 760 & 750.743 & 2224 \\
\hline 315.028 & 1597 & 751.081 & 1099 \\
\hline 378.767 & 514 & 784.496 & 1510 \\
\hline 393.22 & 543 & 786.022 & 4880 \\
\hline 393.72 & 1146 & 786.862 & 4392 \\
\hline 475.135 & 621 & 813.048 & 1287 \\
\hline 484.371 & 1115 & 813.159 & 11579 \\
\hline 484.921 & 531 & 835.634 & 2315 \\
\hline 490.072 & 7334 & 835.845 & 4306 \\
\hline 490.762 & 19858 & 838.906 & 0.64 \\
\hline 524.115 & 2205 & 839.705 & 3847 \\
\hline 524.644 & 6675 & 892.829 & 7458 \\
\hline 573.46 & 744 & 902.098 & 5122 \\
\hline 577.852 & 1390 & 902.16 & 47060 \\
\hline 578.168 & 5378 & 903.064 & 12132 \\
\hline 579.53 & 1102 & 903.867 & 13428 \\
\hline 580.059 & 577 & 932.277 & 4584 \\
\hline 646.969 & 990 & 932.513 & 2620 \\
\hline 647.105 & 3758 & 948.68 & 41626 \\
\hline 670.053 & 1683 & 952.71 & $4.12 \mathrm{E}+08$ \\
\hline 670.471 & 813 & 967.912 & 8302 \\
\hline 677.37 & 838 & 971.89 & $1.34 \mathrm{E}+07$ \\
\hline 721.767 & 56720 & & \\
\hline
\end{tabular}


Table 7: MWS simulation of frequencies, mode configurations, and R/Qs in the $56 \mathrm{MHz}$ cavity with 4 modified dampers inserted in asymmetrical chemical ports. (M, monopole; D, dipole; S, sextupole; and. Q, quadrupole)

\begin{tabular}{|c|c|c|c|c|c|c|c|}
\hline $\begin{array}{c}\text { Frequency } \\
{[\mathrm{MHz}]}\end{array}$ & $\begin{array}{l}\text { Mode } \\
\text { Config. }\end{array}$ & $\mathrm{R} / \mathrm{Q}[\Omega]$ & $\mathrm{R}_{\mathrm{SH}}[\Omega / \mathrm{cm}]$ & $\begin{array}{c}\text { Frequency } \\
{[\mathrm{MHz}]}\end{array}$ & $\begin{array}{l}\text { Mode } \\
\text { Config. }\end{array}$ & $\mathrm{R} / \mathrm{Q}[\Omega]$ & $\mathrm{R}_{\mathrm{SH}}[\Omega / \mathrm{cm}]$ \\
\hline 56.231 & $M$ & 80.53 & 562 & 722.661 & $S$ & $2.49 \mathrm{E}-05$ & 0.11 \\
\hline 167.456 & M & 32.34 & 105 & 726.747 & Q & 0.00106 & 0.15 \\
\hline 260.445 & $\mathrm{D}$ & 22.18 & 4618 & 726.786 & Q & 0.0014 & 0.93 \\
\hline 261.133 & $\mathrm{D}$ & 17.38 & 2395 & 746.283 & S & 0.000477 & 1.17 \\
\hline 278.583 & M & 25.4 & 81 & 747.159 & S & 0.00046 & 0.71 \\
\hline 314.605 & $\mathrm{D}$ & 16.58 & 830 & 750.743 & $\mathrm{D}$ & 21.44 & 7497 \\
\hline 315.028 & $\mathrm{D}$ & 9.65 & 1017 & 751.081 & $\mathrm{D}$ & 22.43 & 3877 \\
\hline 378.767 & M & 27.77 & 106 & 784.496 & M & 3.74 & 42 \\
\hline 393.22 & $\mathrm{D}$ & 19.17 & 857 & 786.022 & S & 0.0555 & 44.6 \\
\hline 393.72 & $\mathrm{D}$ & 8.38 & 792 & 786.862 & S & 0.00594 & 4.30 \\
\hline 475.135 & M & 22.63 & 104 & 813.048 & Q & 0.00123 & 0.27 \\
\hline 484.371 & $\mathrm{D}$ & 19.73 & 2231 & 813.159 & Q & 0.00102 & 2.01 \\
\hline 484.921 & $\mathrm{D}$ & 8.43 & 455 & 835.634 & $\mathrm{D}$ & 6.86 & 2778 \\
\hline 490.072 & $\mathrm{Q}$ & 0.000874 & 0.66 & 835.845 & $\mathrm{D}$ & 7.34 & 5534 \\
\hline 490.762 & $\mathrm{Q}$ & 0.00125 & 2.55 & 838.906 & S & 0.00236 & $2.6 \mathrm{E}-4$ \\
\hline 524.115 & $\mathrm{Q}$ & 0.00056 & 0.14 & 839.705 & S & 0.00528 & 3.57 \\
\hline 524.644 & Q & 0.000656 & 0.48 & 892.829 & M & 2.63 & 146 \\
\hline 573.46 & M & 12.91 & 71 & 902.098 & Q & 0.000988 & 0.96 \\
\hline 577.852 & $\mathrm{Q}$ & 0.081 & 13.6 & 902.16 & Q & 0.0069 & 61.4 \\
\hline 578.168 & Q & 0.0405 & 26.4 & 903.064 & S & 0.000843 & 1.93 \\
\hline 579.53 & $\mathrm{D}$ & 19.68 & 2633 & 903.867 & S & 0.000321 & 0.82 \\
\hline 580.059 & $\mathrm{D}$ & 9.28 & 651 & 932.277 & $\mathrm{D}$ & 2.68 & 2395 \\
\hline 646.969 & $\mathrm{Q}$ & 0.0016 & 0.21 & 932.513 & $\mathrm{D}$ & 2.78 & 1422 \\
\hline 647.105 & $\mathrm{Q}$ & 0.00211 & 1.07 & 948.68 & $\mathrm{O}$ & $9.83 \mathrm{E}-06$ & 0.08 \\
\hline 670.053 & $\mathrm{D}$ & 19.30 & 4557 & 952.71 & $\mathrm{O}$ & $8.44 \mathrm{E}-08$ & 6.94 \\
\hline 670.471 & $\mathrm{D}$ & 26.12 & 2982 & 967.912 & $\mathrm{O}$ & $2.32 \mathrm{E}-05$ & 0.04 \\
\hline 677.37 & M & 6.63 & 41 & 971.89 & $\mathrm{O}$ & $3.50 \mathrm{E}-08$ & 0.10 \\
\hline 721.767 & S & 4.91E-05 & 0.42 & & & & \\
\hline
\end{tabular}

The $\mathrm{R} / \mathrm{Qs}$ and shunt impedances in Table 7 has the same definition as that given in section 2.2.

Table 6 is the frequency table in such geometry. The loaded Qs for all monopole and dipole modes are $4 \times 10^{\mathrm{a}}$. Those loaded Qs for all quadrupoles are ${ }^{\prime \prime} \mathbf{5} \times 10^{4}$. All R/Q for HOM's are $x_{n}^{\prime \prime} 33 \Omega$, and all shunt impedance values are $\alpha_{n}^{4} 7.5 \times 10^{8} \Omega / \mathrm{cm}$. The higher order 
modes are very well damped in this configuration. The HOM damping effect in such geometry meets with the requirements for the cavity.

\section{Acknowledgement}

The authors would like to thank M. Blaskiewicz for his advice and helpful discussion. The authors would also like to thank C. Pai and M. Grau for providing the simulation and design figures. 


\section{Reference}

[1] I. Ben-Zvi, C-A/AP/337, 2009.

[2] E. Choi, H. Hahn, C-A/AP/319, 2008.

[3] CST Microwave Studio Suite 2008.

[4] ANSYS v11.0.

[5] Private discussion with M. Grau.

[6] Private discussion with C. Pai. 